
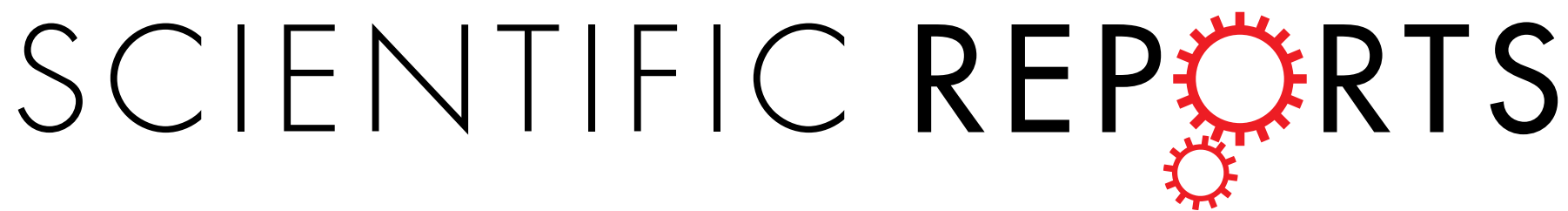

\title{
Highly Dispersed NiO Nanoparticles Decorating graphene Nanosheets for Non-enzymatic Glucose Sensor and Biofuel Cell
}

\author{
Guisheng Zeng ${ }^{1}$, Weiping $\mathrm{Li}^{1,2}$, Suqin $\mathrm{Ci}^{1}$, Jingchun $\mathrm{Jia}^{2,3}$ \& Zhenhai Wen ${ }^{1,2,3}$
}

Nickel oxide-decorated graphene nanosheet (NiO/GNS), as a novel non-enzymatic electrocatalyst for glucose oxidation reaction (GOR), was synthesized through a facile hydrothermal route followed by the heat treatment. The successful synthesis of NiO/GNS was characterized by a series of techniques including XRD, BET, SEM and TEM. Significantly, the NiO/GNS catalyst show excellent catalytic activity toward GOR, and was employed to develop a sensitive non-enzymatic glucose sensor. The developed glucose sensor could response to glucose in a wide range from $5 \mu \mathrm{M}-4.2 \mathrm{mM}$ with a low detection limit (LOD) of $5.0 \mu \mathrm{M}(\mathrm{S} / \mathrm{N}=3)$. Importantly, compared with bare NiO, the catalytic activity of NiO/GNS was much higher. The reason might be that the 2D structure of graphene could prevent the aggregation of $\mathrm{NiO}$ and facilitate the electron transfer at electrode interface. Moreover, the outstanding catalytic activity of NiO/GNS was further demonstrated by applying it to construct a biofuel cell using glucose as fuel, which exhibited high stability and current density.

Since Clark and Lyons reported the first biosensor based on enzyme electrode in 1962, tremendous effort has been directed toward research in developing high-performance glucose enzyme biosensors due to their potential application in various fields, such as medical diagnosis, diabetes management, bioprocess monitoring, beverage industry, and environmental monitoring ${ }^{1}$. The traditional enzyme-based glucose biosensor are typically immobilized the glucose oxidase on various substrates including silica ${ }^{2}, \mathrm{TiO}_{2}$ nanotube arrays ${ }^{3}$, carbon nanotubes $(\mathrm{CNTs})^{4}, \mathrm{Au}$ and $\mathrm{ZnO}$ etc. ${ }^{5-8}$. Although enzyme based glucose sensors have advantage of high sensitivity and selectivity, the activity and stability of enzyme are highly dependent on environmental conditions, such as $\mathrm{pH}$, temperature and other factors ${ }^{9}$. Therefore, it is highly desirable to explore non-enzymatic electrocatalyst with high activity and excellent stability for catalyzing glucose oxidation.

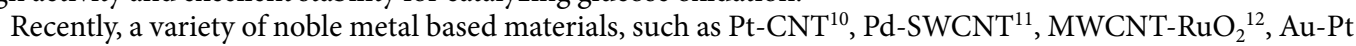
alloy $^{13}$, Pt-Ir alloy ${ }^{14}$ etc., have been investigated as electrocatalysts of GOR for developing biosensor or biofuel cell device. However, these electrocatalytic materials are noble and rare metal with expensive price; moreover, they are vulnerable to the chemisorbed intermediates and adsorbed chloride ion ${ }^{15}$. In recent years, the transitional metal (e.g. Fe, Co and $\mathrm{Ni}$ ) compounds have received intensive research interests as cost effective elecctrocatalysts for $\mathrm{GOR}^{16-23}$. Among them, Ni-based material is one of the most competitive candidates because of their low toxicity, low price, good stability, and high catalytic activity toward GOR. Unfortunately, the poor electrical conductivity of Ni-based materials increases both the sheet resistance and the charge transfer resistance of the electrode, which in work reported to date have led to a poor catalytic activity or sensing performance ${ }^{24}$. Therefore, carbon nanomaterials, such as $\mathrm{CNT}^{19}$, activated carbon and graphene ${ }^{25}$, are usually designed to be the supports of these poor conductive material to enhance their conductivity and improve the effective contact area. For instance, graphene-cobalt oxide ${ }^{26}$ and nickel oxide on CVD-grown graphene ${ }^{27}$ have been used for non-enzymatic glucose sensor. Due to extraordinary electrical and physicochemical properties, graphene has become one of the most

${ }^{1}$ Key Laboratory of Jiangxi Province for Persistent Pollutants Control and Resources Recycle, Nanchang Hangkong University, Nanchang 330063, P. R. China. ${ }^{2}$ Key Laboratory of Design and Assembly of Functional Nanostructures, Fujian Institute of Research on the Structure of Matter, Chinese Academy of Sciences, Fuzhou, Fujian 350002, P. R. China. ${ }^{3}$ Fujian Provincial Key Laboratory of Nanomaterials, Fujian Institute of Research on the Structure of Matter, Chinese Academy of Sciences, Fuzhou, Fujian 350002, P. R. China. Correspondence and requests for materials should be addressed to Z.W. (email: wenzhenhai@yahoo.com or wen@firsm.ac.cn) 
competitive additives employed to advance the functionality of $\mathrm{Co}$, Ni-based compound. Besides, the introduction of graphene also bring lots of active sites that tightly attaching metal oxide nanoparticles, which potentially provide additional advantage to prevent the agglomeration of active material during their catalytic process and thus are more stable and practical upon application.

In this paper, we reported the fabrication of graphene nanosheets supported highly dispersed $\mathrm{NiO}$ nanoparticles $(\mathrm{NiO} / \mathrm{GNS})$ via a simple and convenient hydrothermal method. Electrochemical tests demonstrated that the $\mathrm{NiO} / \mathrm{GNS}$ nanostructures exhibit excellent catalytic activity and high selectivity toward GOR, directing us to develop a high-performance non-enzyme glucose biosensor. In addition, to our best knowledge, this is the first demonstration of a low cost and enzymeless glucose biofuel cell device with the $\mathrm{NiO} /$ graphene as the electrode material.

\section{Experimental}

Chemicals and reagents. Graphene oxide hydrosol (Chinese Academy of Sciences, Shanxi Institute of Coal Chemistry); All other reagents, purchased from Xilong Chemical and Hefei Bomei Biological Technology, were of analytical grade and used as received without further purification. All solutions were freshly prepared with Milli-Q deionized (DI) water.

Material synthesis. Typically, the NiO/GNS materials were prepared as follows: $0.1 \mathrm{~g}$ sodium dodecyl sulfate (SDS) was dissolved in $30 \mathrm{~mL}$ of graphene oxide (GO) aqueous solution $\left(5.0 \mathrm{mg} \mathrm{mL}^{-1}\right)$ at room temperature. Then, $5.0 \mathrm{mmol}(1.19 \mathrm{~g})$ nickel chloride hexahydrate $\left(\mathrm{NiCl}_{2} \bullet 6 \mathrm{H}_{2} \mathrm{O}\right)$ were added into the solution with vigorous magnetic stirring until they are completely dissolved. Afterwards, $30 \mathrm{~mL}$ of ethanol and $5.0 \mathrm{mmol}(0.3 \mathrm{~g}) \mathrm{of}$ urea were added into the solution with vigorous magnetic stirring. After stirring for 10 minutes, the mixed solution were transferred to a $100 \mathrm{~mL}$ Teflon-lined stainless steel autoclave and heated at $160^{\circ} \mathrm{C}$ for $10 \mathrm{~h}$. After cooling to room temperature, the products were filtered and washed with distilled water and absolute alcohol for three times, respectively. The dried black powder was annealed at $500^{\circ} \mathrm{C}$ for $5 \mathrm{~h}$ in $\mathrm{Ar}$ flow, with a heating rate of $5^{\circ} \mathrm{C}$ $\mathrm{min}^{-1}$. The product was named nickel oxide/graphene nanosheets (NiO/GNS). For comparison, the bare $\mathrm{NiO}$ samples were prepared in accordance with the above procedure without GO solution.

Material characterization. Powder X-ray diffraction (XRD) was conducted on a D8 ADVANCE (Bruker) powder diffractometer. The structure and morphology of the samples were characterized using a scanning electron microscope (Nova Nano SEM450, FEI) and a transmission electron microscopy (TEM, JEM-2010). Specific surface area, pore volume and pore size distributions were tested at $77.3 \mathrm{~K}$ through Brunauer-Emmett-Teller (BET, Quantachrome Nova) nitrogen adsorption-desorption.

Electrode preparation and electrochemical measurement. To prepared the working electrode, $5 \mathrm{mg}$ electrode materials (NiO/GNS or $\mathrm{NiO}$ ) and $0.05 \mathrm{~mL}$ Nafion solution (DuPont) were added into $0.45 \mathrm{~mL}$ water, then sonicated for $30 \mathrm{~min}$ and formed a homogeneous suspension. The electrode was prepared by dripped $6.0 \mu \mathrm{L}$ of the suspension onto glassy carbon electrode (GCE, diameter $3 \mathrm{~mm}$, polished with 0.05 -micron alumima paste); the modified electrode after drying was then used as the working electrode. Cyclic voltammetry and current-time curve data were recorded by an electrochemical workstation (CHI 660D), using a Pt wire as the counter electrode and $\mathrm{Ag} / \mathrm{AgCl}$ (saturated $\mathrm{KCl}$ ) as the reference electrode. Before the measurement, the $0.1 \mathrm{M} \mathrm{NaOH}$ aqueous solution was purged with Ar for $\sim 15$ mins to remove the dissolved oxygen. For fabricating glucose fuel cell, a slurry was prepared by mixing the $\mathrm{NiO} / \mathrm{GNS}$ sample, acetylene black, and polyvinylidene fluoride (PVDF) at a weight ratio of 80:15:5, using N-methyl-2-pyrrolidone (NMP) as a solvent; the mixture was then uniformly coated on the carbon cloth $(1.5 \mathrm{~cm} \times 2 \mathrm{~cm})$ with a mass loading of about $5.0 \mathrm{mg} \mathrm{cm}^{-2}$. The cathode electrode was prepared by the same method using the commercial Pt/C (20 wt\%) instead of NiO/GNS. A batch-type microbial fuel cell (MFC) with two chambers was constructed by connecting two glass bottles ( $25 \mathrm{~mL}$, Phychemi, Beijing) with an anion-exchange membrane (AEM, Membrane International Inc., Ringwood, NJ, USA) as a separator. The cell voltage was recorded by a digital multimeter (Keithley Instruments, Inc.).

\section{Results and Discussion}

Characterization. The X-ray diffraction analysis was performed to characterize the samples on a small panel. Figure 1a shows the typical powder XRD pattern of the bare $\mathrm{NiO}$ and the $\mathrm{NiO} / \mathrm{GNS}$ nanoparticles. Both samples exhibits three prominent peaks at the 2 Theta value of $37.3^{\circ}, 43.4^{\circ}$ and $62.9^{\circ}$, which can be well indexed as (111), (200) and (220) crystal planes of the NiO phase (JCPDS NO. 01-078-0429), respectively. The results showed that $\mathrm{Ni}(\mathrm{OH})_{2}$ has been completely converted to a pure phase $\mathrm{NiO}$ after annealing at $500^{\circ} \mathrm{C}$ under Ar atmosphere. Addition of graphene made the diffraction peaks weaker and broader, suggesting the smaller crystallite sizes of $\mathrm{NiO}$ nanoparticles in $\mathrm{NiO} / \mathrm{GNS}$ as compared with the bare $\mathrm{NiO}$. The two new weak peaks at $44.9^{\circ}$ and $51.8^{\circ}$ observed over the $\mathrm{NiO} / \mathrm{GNS}$ that are assigned to face-centered-cubic (fcc) Ni since the graphene nanosheets can probably induced partly reduction of the $\mathrm{NiO}$ nanoparticles anchored on the graphene nanosheets ${ }^{28}$. Figure $1 \mathrm{~b}$ shows the nitrogen adsorption-desorption isotherm for NiO/GNS, which exhibited the type IV isotherms with a distinct hysteresis loop at a relative pressure $\mathrm{P} / \mathrm{P}_{0}$ ranging from 0.5 to 1.0. According to the IUPAC nomenclature, this curve is a typical difference between the adsorption and desorption of mesoporous material. The shape of the hysteresis loop is associated with silt-like pores formed by the aggregations of $\mathrm{NiO}$ nanoparticles, suggesting the sample is composed of sheet-like graphene decorated with $\mathrm{NiO}^{29}$. The as-prepared $\mathrm{NiO} / \mathrm{GNS}$ samples possess a BET surface area of $135.8 \mathrm{~m}^{2} / \mathrm{g}$, a pore volume of $\sim 0.504 \mathrm{~cm}^{3} / \mathrm{g}$, and an average pore size of $\sim 14.8 \mathrm{~nm}$.

The morphology and structure of the $\mathrm{NiO}$ and $\mathrm{NiO} / \mathrm{GNS}$ samples were examined by SEM and TEM. Figure $2 \mathrm{a}$ is the SEM image of the bare $\mathrm{NiO}$ sample, indicating the $\mathrm{NiO}$ nanoparticles had a nanorod morphology with a diameter of around $60 \mathrm{~nm}$ and a length ranging of $200-400 \mathrm{~nm}$; they are agglomerated together forming a block product. Figure $2 \mathrm{~b}$ displays the typical SEM image of NiO/GNS, revealing the composites have a nanosheets 

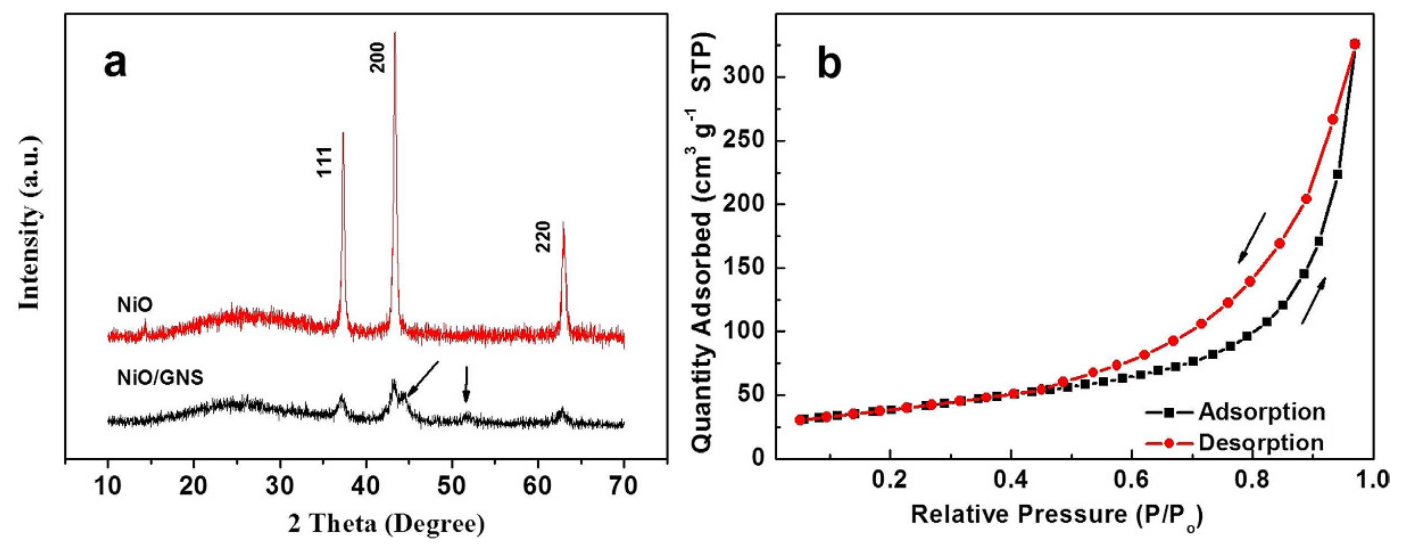

Figure 1. (a) XRD patterns of $\mathrm{NiO}$ and $\mathrm{NiO} / \mathrm{GNS}$. (b) The BET image of $\mathrm{NiO} / \mathrm{GNS}$.
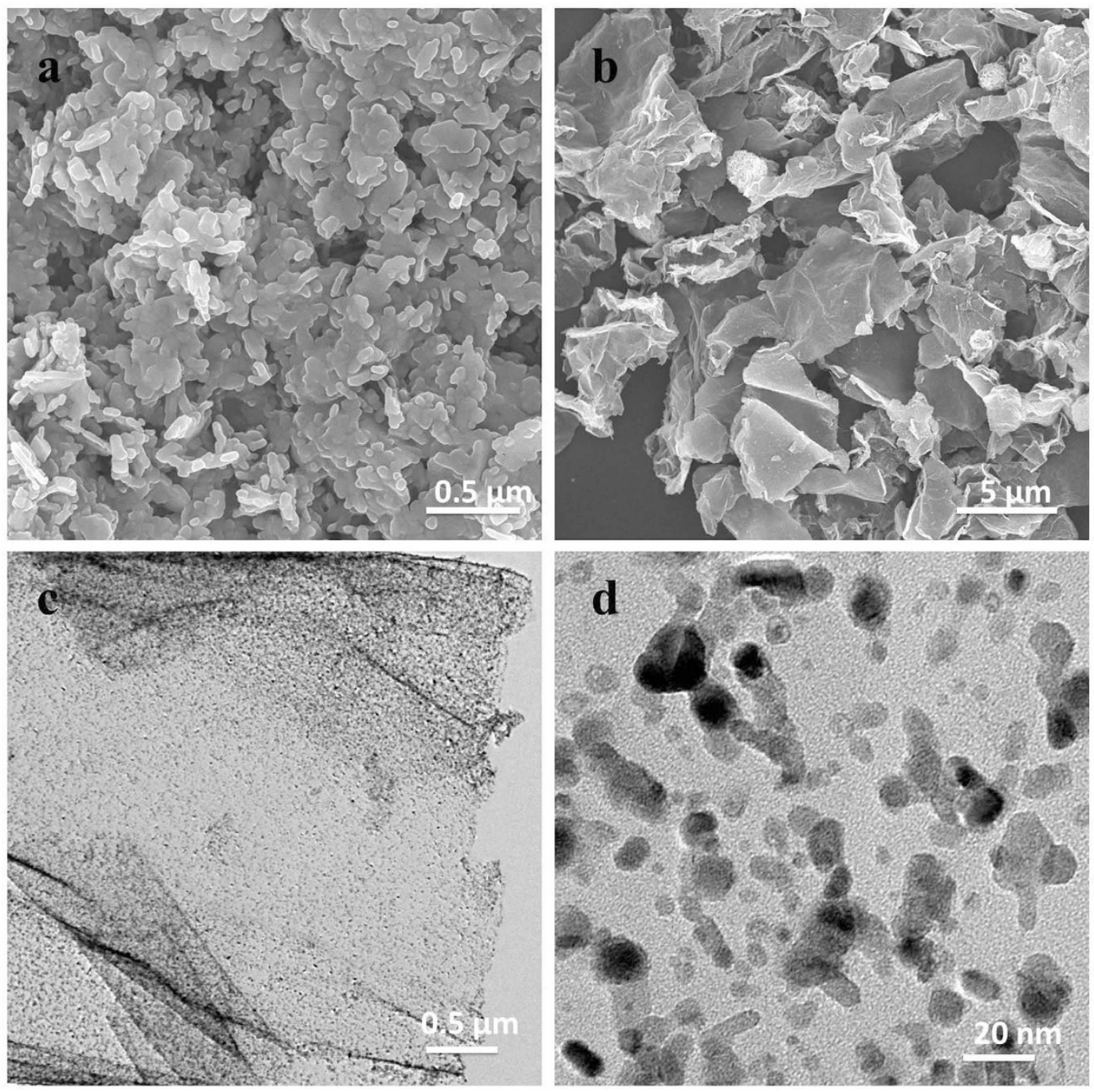

Figure 2. (a,b) Typical FESEM images of $\mathrm{NiO}$ and $\mathrm{NiO} / \mathrm{GNS}$. (c,d) TEM images of NiO/GNS with different magnification.

morphology and crumpled structure on graphene surface, probably arising from the hydrothermal treatment. The NiO nanoparticles (white dots) are uniformly dispersed on graphene surface, demonstrating that graphene plays a key role in producing smaller $\mathrm{NiO}$ nanoparticles and preventing the agglomeration of $\mathrm{NiO}$ nanoparticles. 

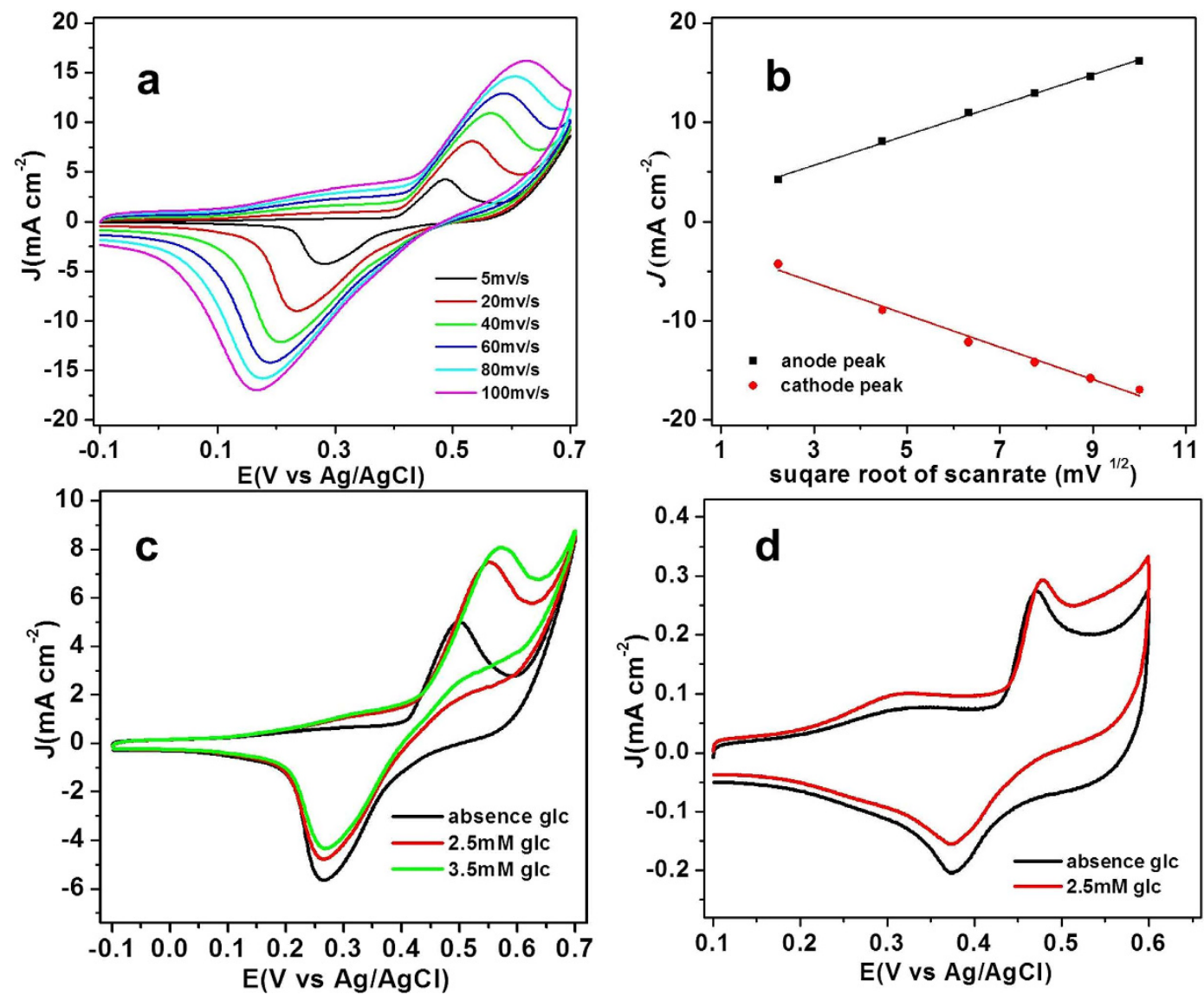

Figure 3. (a) $\mathrm{CVs}$ of the $\mathrm{NiO} / \mathrm{GNS}$ in $0.1 \mathrm{M} \mathrm{NaOH}$ at different scan rates $\left(5-100 \mathrm{mV} \mathrm{s}^{-1}\right)$. (b) Relationship between $\mathrm{J}_{\text {and }} \mathrm{v}^{1 / 2}$ for CVs of the $\mathrm{NiO} / \mathrm{GNS}$ in $0.1 \mathrm{M} \mathrm{NaOH}$. (c) CVs of the $\mathrm{NiO} / \mathrm{GNS}$ in $0.1 \mathrm{M} \mathrm{NaOH}$ in the absence and presence of glucose at a scan rate $10 \mathrm{mVs}^{-1}$. (d) $\mathrm{CVs}$ of the $\mathrm{NiO}$ in $0.1 \mathrm{M} \mathrm{NaOH}$ in the absence of glucose and the presence of glucose at a scan rate of $10 \mathrm{mVs}^{-1}$.

For TEM images of the NiO/GNS (Fig. 2c), one can observe a large amount of nanoparticles uniformly anchored on the graphene surface. In addition, Fig. $2 \mathrm{~d}$ shows the high resolution TEM (HRTEM) image, demonstrating that the $\mathrm{NiO}$ has a nanoparticle size ranging from $15 \mathrm{~nm}$ to $30 \mathrm{~nm}$ and strongly anchored on the surface of graphene nanosheets.

Electrocatalysis of glucose oxidation. The electrochemical properties of NiO/GNS were firstly investigated using CV technique in Ar-saturated $0.1 \mathrm{M} \mathrm{NaOH}$ solution at various scan rate $\left(5 \sim 100 \mathrm{mV} \mathrm{s}^{-1}\right)$ as shown in Fig. 3a. A couple of redox peaks for the $\mathrm{NiO} / \mathrm{GNS}$ are observed at the potential from -0.1 to $0.7 \mathrm{~V}$ for $\mathrm{NiO} / \mathrm{GNS}$ electrode, which could be attributed to the redox reaction between $\mathrm{NiO}$ and $\mathrm{NiOOH}$, respectively ${ }^{24}$. In addition, the anodic peak shows a slight positive shift accompanying with negatively moving of the cathodic peak with the increase of scan rate, which is consistent with peak potentials shift toward the formal potential as period is increased for the quasi-reversible mechanism, suggesting a quasi-reversible electron transfer reaction for the above electrochemical reaction ${ }^{30}$. Additionally, Fig. $3 \mathrm{~b}$ shows the relationship between the peak current density and the square root of the scan rate, the peak current densities for both the oxidation and reduction is proportional to the square root of the scan rate, suggesting that the electrochemical reaction occurring on the surface of the $\mathrm{NiO} / \mathrm{GNS}$ is a diffusion-controlled process $^{31}$.

The electrocatalytic activity of $\mathrm{NiO} / \mathrm{GNS}$ toward GOR was studied in $0.1 \mathrm{M} \mathrm{NaOH}$ solution with the presence of a certain amount of glucose. Figure $3 \mathrm{c}$ presents the CVs in the absence and the presence of $2.5 \mathrm{mM}$ and $3.5 \mathrm{mM}$ glucose in $0.1 \mathrm{M} \mathrm{NaOH}$ at the $\mathrm{NiO} / \mathrm{GNS}$ electrode with a scan rate of $10 \mathrm{mV} \mathrm{s}^{-1}$. As expected, the anodic peak current increased with addition of glucose, and the peak intensity enhanced with the increase of glucose concentration. The addition of glucose causes remarkable increase in anodic peak current, while the cathodic peak current slightly decreased. And the glucose is electrocatalyzed into glucolactone at the $\mathrm{NiO} / \mathrm{GNS}$ electrode by the $\mathrm{NiO} / \mathrm{NiOOH}$ redox couple according to the following reactions ${ }^{32}$ :

$$
\begin{gathered}
\mathrm{NiO}+\mathrm{OH}^{-} \leftrightarrow \mathrm{NiOOH}+\mathrm{e}^{-} \\
\mathrm{NiOOH}+\text { glucose } \rightarrow \mathrm{NiO}+\text { glucolactone }
\end{gathered}
$$



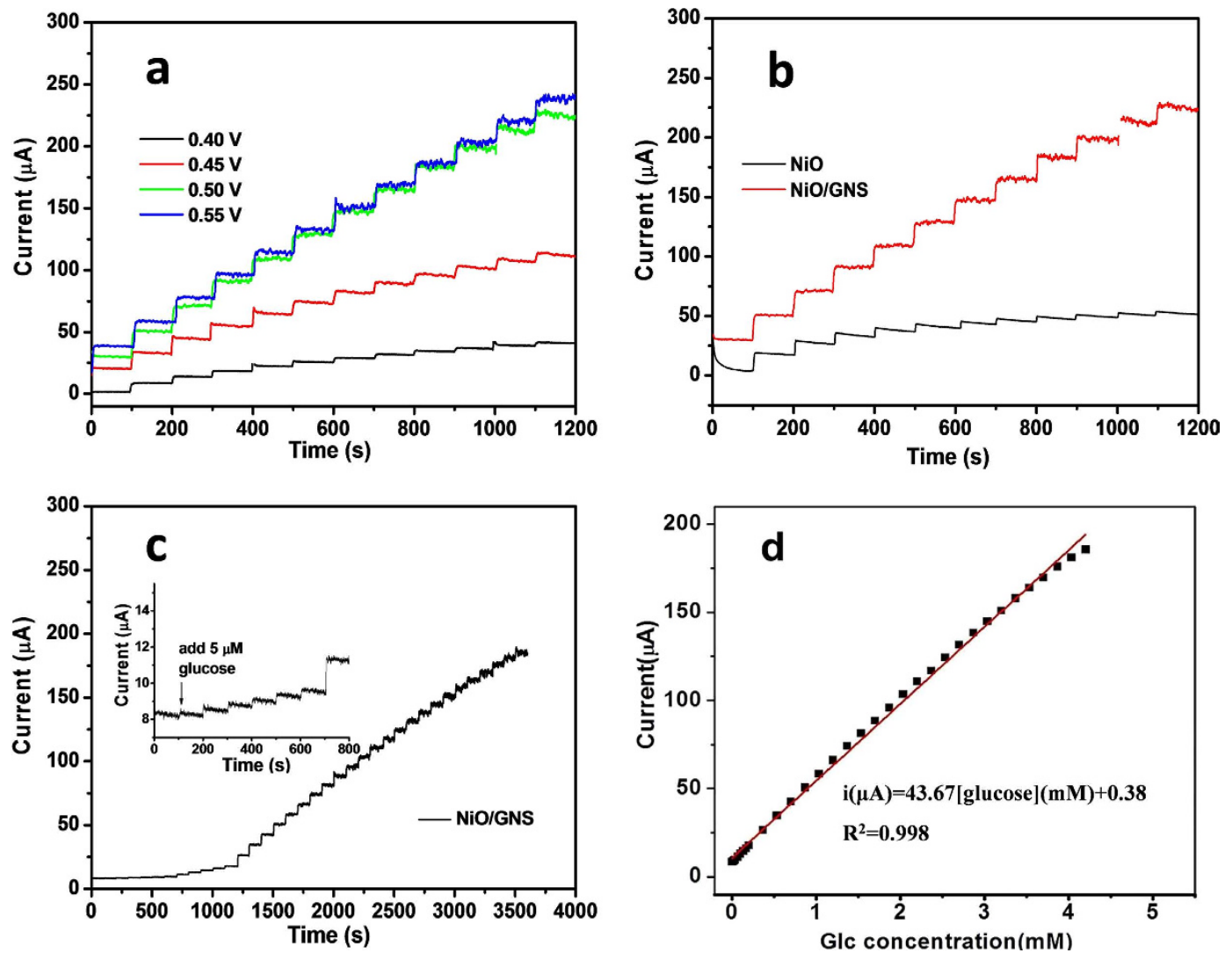

Figure 4. (a) Amperometric response of the $\mathrm{NiO} / \mathrm{GNS}$ with successive addition of $0.5 \mathrm{mM}$ glucose into $0.1 \mathrm{M}$ $\mathrm{NaOH}$ solution at different potentials. (b) Amperometric response of the $\mathrm{NiO}$ and the $\mathrm{NiO} / \mathrm{GNS}$ with the successive addition of $0.5 \mathrm{mM}$ glucose at $0.50 \mathrm{~V}$. (c) Amperometric response of the $\mathrm{NiO} / \mathrm{GNS}$ to successive addition of glucose at $0.5 \mathrm{~V}$; inset: amperometric response to $5.0 \mu \mathrm{M}$ glucose. (d) The corresponding calibration curve at the $\mathrm{NiO} / \mathrm{GNS}$ eletrode.

The remarkable increase of the anodic peak current demonstrates the NiO/GNS/GCE has strongly electrochemical response upon glucose oxidation. As described in the equation (1) and (2), the catalytic process is accompanied with the redox reaction between divalent $\mathrm{Ni}$ and trivalent $\mathrm{Ni}$. Therefore, it is reasonable that the reduction current decrease slightly with the addition glucose due to the consumption of the trivalent Ni by glucose oxidation. Figure 3d shows the CV responses in the absence of glucose and the presence of $2.5 \mathrm{mM}$ glucose. According to the experimental results, the bare $\mathrm{NiO}$ exhibits a much smaller current response to the same amount of glucose as compared with the $\mathrm{NiO} / \mathrm{GNS}$ electrode, demonstrating that the $\mathrm{NiO} / \mathrm{GNS}$ significantly improved the catalytic activity on glucose oxidation than that of bare $\mathrm{NiO}$ due to improved conductivity (Fig. S1).

Since the applied potential is one of the key factors in affecting the electrochemical signal response and realizing selective determination of glucose, it is thus of great importance to conduct comparison experiment to optimize the working potential of glucose electrochemical sensor. Figure 4a exhibits the amperometric response of the $\mathrm{NiO} / \mathrm{GNS}$ electrode to successive additions of $0.5 \mathrm{mM}$ glucose at different applied potentials. The steady-state current response increased drastically when the applied potential was tuned from $0.40 \mathrm{~V}$ to $0.55 \mathrm{~V}$ upon addition of glucose. However, when the potential rose to $0.55 \mathrm{~V}$, the amperometric response did not increase significantly. Given that the lower potential tend to result in a smaller background current or noise, while a higher potential may induce interrupt signal from a lot of interference species, $0.50 \mathrm{~V}$ was selected as the optimum working potential for the amperometric measurement in the later studies. It should be noted that the bare $\mathrm{NiO}$ only shows a slight current response with addition of glucose, much poorer than that of the NiO/GNS (Fig. 4b), which is basically consistent with the behavior observed in the CV results (Fig. 3d).

The sensitivity of the $\mathrm{NiO} / \mathrm{GNS}$ electrode toward glucose was evaluated by amperometric measurements at a constant potential of $0.50 \mathrm{~V}$. Figure $4 \mathrm{c}$ shows the typical amperometric response of the NiO/GNS electrode to the successive step-wise addition of glucose into the stirring electrolyte $(0.1 \mathrm{M} \mathrm{NaOH})$ with a time interval of around $100 \mathrm{~s}$. When the concentration of glucose raise to $5.0 \mu \mathrm{M}$, the NiO/GNS electrode shows an observable response and achieve the maximum steady-state current within 5s (the inset Figure in Fig. 4c, partially enlarged figure), implying the catalytic reaction of glucose oxidation is promptly activated on the surface of the $\mathrm{NiO} / \mathrm{GNS}$ electrode. Figure $4 \mathrm{~d}$ presents the calibration plot of glucose concentration and the corresponding current density, demonstrating the $\mathrm{NiO} / \mathrm{GNS}$ electrode shows a good linear relationship over a wide concentration range of $5.0 \mu \mathrm{M}-4.2 \mathrm{mM}$ glucose with a slope of $46.67 \mu \mathrm{A} \mathrm{mM}^{-1}$ and a correlation coefficient of 0.998 . The sensitivity of the $\mathrm{NiO} / \mathrm{GNS}$ sensor is calculated to be $666.71 \mu \mathrm{A} \mathrm{mM}^{-1} \mathrm{~cm}^{-2}$ by dividing the slope of the linear regression equation 

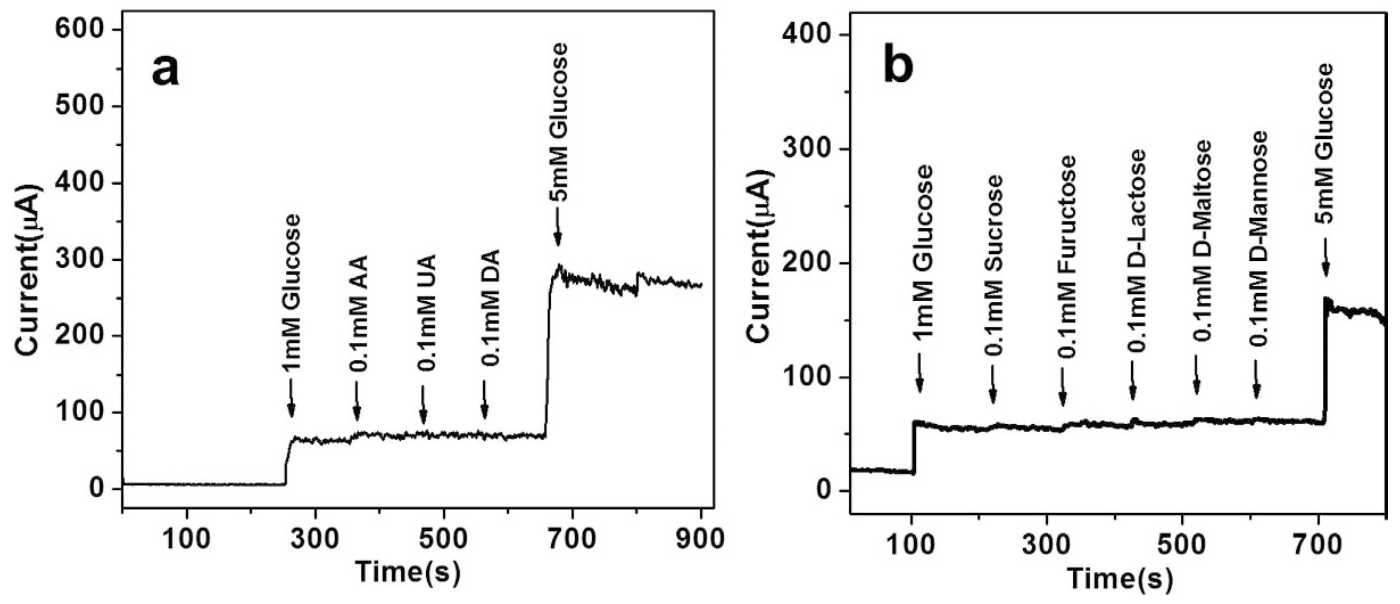

Figure 5. (a) Amperometric response of the $\mathrm{NiO} / \mathrm{GNS}$ to successive addition of $0.1 \mathrm{mM}$ AA, $0.1 \mathrm{mM} \mathrm{UA}$, $0.1 \mathrm{mM}$ DA to glucose at an applied potential of $0.50 \mathrm{~V}$. (b) Amperometric response of the NiO/GNS to successive addition of $0.1 \mathrm{mM}$ Sucrose, Fructose, D-Lactose, D-maltose, D-Mannose to glucose aqueous solution.
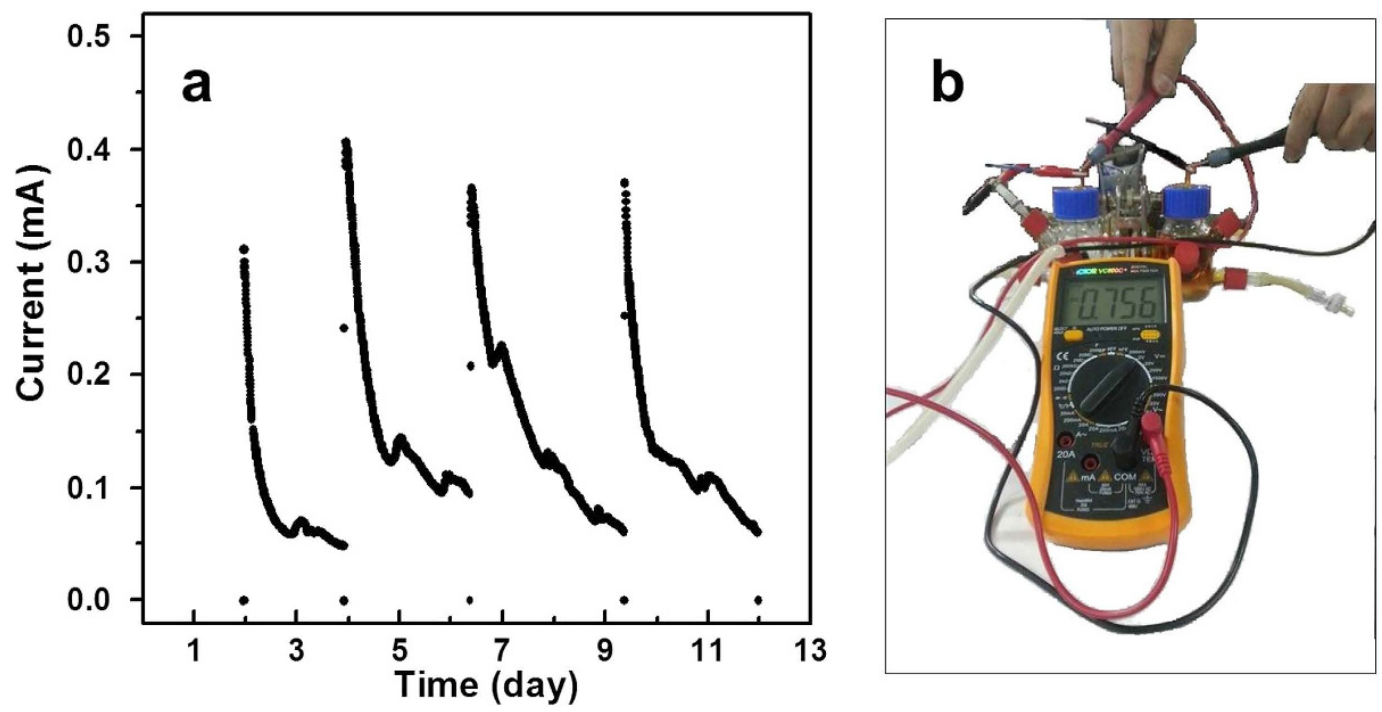

Figure 6. (a) The electrochemical oxidation of $\mathrm{NiO} / \mathrm{GNS} \| \mathrm{Pt} / \mathrm{C}$ fuel cell, using $0.1 \mathrm{M} \mathrm{KOH}$ solution and $0.1 \mathrm{M}$ $\mathrm{KOH}$ solution containing $0.1 \mathrm{M}$ glucose as catholyte and anolyte. (b) the schematic diagram of fuel cell test for open circuit voltage.

by the electrode surface area, this value stands on the medium level relating to the previously reported graphene or the $\mathrm{NiO}$-based glucose biosensors ${ }^{24,31,33-35}$. Additionally, based on a signal-to-noise ratio of $3(\mathrm{~S} / \mathrm{N})$, a lower detection limit of $5.0 \mu \mathrm{M}$ can be obtained.

Interference study and long-term test. The interference in nonenzymatic glucose sensor is a big challenge because a few of endogenous interfering species, such as ascorbic acid (AA), dopamine (DA), and uric acid (UA), usually co-exist with glucose in human blood ${ }^{36}$. And the level of glucose $(3-8 \mathrm{mM})$ is much higher than these species $(<0.5 \mathrm{mM})^{37}$. Therefore, we carried out interference study by adding $1.0 \mathrm{mM}$ glucose in electrolyte during amperometric measurement at a constant potential of $0.50 \mathrm{~V}$, followed by successively adding $0.1 \mathrm{mM}$ AA, $0.1 \mathrm{mM}$ UA, and $0.1 \mathrm{mM}$ DA to mimic the interference. As shown in Fig. 5a, the NiO/GNS exhibits excellent selectivity for GOR, the corresponding oxidation current change is $56.2 \pm 0.3 \mu \mathrm{A}$ upon adding $1 \mathrm{mM}$ glucose, which greatly exceeds those recorded for the interfering species, i.e. $6.6 \pm 0.2 \mu \mathrm{A}$ for DA, and almost no current response upon adding UA and AA. In addition, the selectivity of the NiO/GNS sensor towards GOR was also tested in the presence of a set of sugars. Figure $5 \mathrm{~b}$ shows that the corresponding oxidation current response for these sugars is relatively small in comparison with the $5 \mathrm{mM}$ glucose, indicating the NiO/GNS electrode has high selectivity for glucose. These results demonstrate that the NiO/GNS modified electrode has a good selectivity for GOR and is a potential material of nonenzymatic glucose sensor. 
The long-term stability of the $\mathrm{NiO} / \mathrm{GNS}$ sensor was evaluated through the amperometric response of $0.2 \mathrm{mM}$ glucose recorded at intervals over 18 days, and the $\mathrm{NiO} / \mathrm{GNS}$ electrode was stored in refrigerator when not in use. The results indicate that the sensor retains more than $88 \%$ of the initial sensitivity in the long-term tests (Figure S2), suggesting that the non-enzymatic glucose sensor has favorable stability. This excellent durability mainly results from the robust mechanical stability of $2 \mathrm{D}$ graphene.

Glucose fuel cell. Since the $\mathrm{NiO} / \mathrm{GNS}$ shows excellent catalytic activity towards GOR, a non-enzyme glucose fuel cell was fabricated by using the NiO/GNS as anode and the commercial $\mathrm{Pt} / \mathrm{C}$ as cathode. The cell tests were carried out in a batch-type MFC with two chambers separated by an anion-exchange membrane. The anolyte is $0.1 \mathrm{M} \mathrm{KOH}$ aqueous solution containing of $0.1 \mathrm{M}$ glucose, and the catholyte is $0.1 \mathrm{M} \mathrm{KOH}$ aqueous contained dissolved oxygen using a small air pump (shown in Fig. 6b). The open-circuit voltage of the fuel cell reached a relatively considerable voltage up to $0.756 \mathrm{~V}^{38}$. As is shown in Fig. 6a, during every running process the current decreased accordingly with the consumption of glucose with loading of a $100 \mathrm{ohm}$ resistor. However, the current recovered instantly when the electrolyte was refreshed. After four cycles the initial currents of cell still maintained at around $0.3 \mathrm{~mA}$ (corresponding current density: $0.66 \mathrm{~A} \mathrm{~m}^{-2}$ ), also indicating the high stability of the electrode in catalytic reaction.

\section{Conclusions}

In this paper, we developed a reliable strategy to fabricate a composites of highly dispersed nickel oxide nanoparticles decorated graphene nanosheets (NiO/GNS), as an excellent electrocatalysis toward glucose oxidation reaction (GOR). The synthesized NiO/GNS shows fascinating physical and chemical features with mesoporous structure, high surface area, high conductivity, and robust cycle stability. Compared with the bulk $\mathrm{NiO}$, the $\mathrm{NiO} /$ graphene shows significantly improved (two times higher) activity toward catalyzing glucose oxidation reaction. The high catalytic activity of $\mathrm{NiO} / \mathrm{GNS}$ can be attributed to highly dispersed NiO nanoparticles and enhanced electron transfer. Inspiringly, the $\mathrm{NiO} / \mathrm{GNS}$ electrochemical glucose sensor could detect glucose with high sensitivity, possibly providing a low-cost, stable and non-enzymatic point-of-care diagnostics tool for glucose monitoring. Furthermore, the $\mathrm{NiO} /$ graphene was applied as the electrode material of an enzymeless glucose biofuel cell for the first time. The enhanced performance of the NiO/GNS biofuel cell can potentially pave the way of powerful catalyst for energy conversion.

\section{References}

1. Wang, G. et al. Non-enzymatic electrochemical sensing of glucose. Microchim Acta. 180, 161-186 (2013).

2. Li, H. et al. Immobilization of glucose oxidase and platinum on mesoporous silica nanoparticles for the fabrication of glucose biosensor. Electrochim Acta. 56, 2960-2965 (2011).

3. Benvenuto, P., Kafi, A. K. M. \& Chen, A. High performance glucose biosensor based on the immobilization of glucose oxidase onto modified titania nanotube arrays. J Electroanal Chem. 62, 76-81 (2009).

4. Rahman, M. M., Umar, A. \& Sawada, K. Development of amperometric glucose biosensor based on glucose oxidase co-immobilized with multi-walled carbon nanotubes at low potential. Sensor Actuat B-Chem. 137, 327-333 (2009).

5. Wang, H. et al. A novel glucose biosensor based on the immobilization of glucose oxidase onto gold nanoparticles-modified $\mathrm{Pb}$ nanowires. Biosens Bioelectron. 25, 142-146 (2009).

6. Yan, Y. M., Tel-Vered, R., Yehezkeli, O., Cheglakov, Z. \& Willner, I. Biocatalytic Growth of Au Nanoparticles Immobilized on Glucose Oxidase Enhances the Ferrocene-Mediated Bioelectrocatalytic Oxidation of Glucose. Adv Mater. 20, 2365-2370 (2008).

7. Kong, T. et al. An amperometric glucose biosensor based on the immobilization of glucose oxidase on the $\mathrm{ZnO}$ nanotubes. Sensor Actuat B-Chem. 138, 344-350 (2009).

8. Deng, S., Jian, G., Lei, J., Hu, Z. \& Ju, H. A glucose biosensor based on direct electrochemistry of glucose oxidase immobilized on nitrogen-doped carbon nanotubes. Biosens Bioelectron. 25, 373-377 (2009).

9. Yang, X. Y., Tian, G., Jiang, N. \& Su, B. L. Immobilization technology: a sustainable solution for biofuel cell design. Energ Environ Sci. 5, 5540-5563 (2012).

10. Rong, L. Q., Yang, C., Qian, Q. Y. \& Xia, X. H. Study of the nonenzymatic glucose sensor based on highly dispersed Pt nanoparticles supported on carbon nanotubes. Talanta. 72, 819-824 (2007).

11. Meng, L. et al. Nonenzymatic electrochemical detection of glucose based on palladium-single-walled carbon nanotube hybrid nanostructures. Anal chem. 81, 7271-7280 (2009).

12. Tehrani, R. M. \& Ab Ghani, S. MWCNT-ruthenium oxide composite paste electrode as non-enzymatic glucose sensor. Biosens Bioelectron. 38, 278-283 (2012).

13. Wang, X., Yang, T., Feng, Y., Jiao, K. \& Li, G. A Novel Hydrogen Peroxide Biosensor Based on the Synergistic Effect of Gold-Platinum Alloy Nanoparticles/Polyaniline Nanotube/Chitosan Nanocomposite Membrane. Electroanal. 21, 819-825 (2009).

14. Holt-Hindle, P., Nigro, S., Asmussen, M. \& Chen, A. Amperometric glucose sensor based on platinum-iridium nanomaterials. Electrochem Commum. 10, 1438-1441 (2008).

15. Toghill, K. E. \& Compton, R. G. Electrochemical non-enzymatic glucose sensors: a perspective and an evaluation. Int J Electrochem Sci. 5, 1246-1301 (2010).

16. Meher, S. K. \& Rao, G. R. Archetypal sandwich-structured CuO for high performance non-enzymatic sensing of glucose. Nanoscale. 5, 2089-2099 (2013).

17. Zhang, Y. et al. Ultrasensitive and selective non-enzymatic glucose detection using copper nanowires. Biosens Bioelectron. 31, 426-432 (2012).

18. Liu, S., Yu, B. \& Zhang, T. A novel non-enzymatic glucose sensor based on NiO hollow spheres. Electrochim Acta. 102, 104-107 (2013).

19. Li, L. \& Lafdi, K. Nickel modification of carbon nanotubes grown on graphite for electrochemical sensors. Sensor Actuat B-Chem. 132, 202-208 (2008).

20. Cao, X. \& Wang, N. A novel non-enzymatic glucose sensor modified with Fe2O3 nanowire arrays. Analyst. 136, 4241-4246 (2011).

21. Xia, C. \& Ning, W. A novel non-enzymatic electrochemical glucose sensor modified with FeOOH nanowire. Electrochem Commun. 12, 1581-1584 (2010)

22. Lee, K. K., Loh, P. Y., Sow, C. H. \& Chin, W. S. CoOOH nanosheets on cobalt substrate as a non-enzymatic glucose sensor. Electrochem Commun. 20, 128-132 (2012)

23. Dong, X. C. et al. 3D graphene-cobalt oxide electrode for high-performance supercapacitor and enzymeless glucose detection. ACS nano. 6, 3206-3213 (2012). 
24. Guo, C., Wang, Y., Zhao, Y. \& Xu, C. Non-enzymatic glucose sensor based on three dimensional nickel oxide for enhanced sensitivity. Anal Methods. 5, 1644-1647 (2013).

25. Fang, Y. \& Wang, E. Electrochemical biosensors on platforms of graphene. Chem commun. 49, 9526-9539 (2013).

26. Wang, X. et al. A graphene-cobalt oxide based needle electrode for non-enzymatic glucose detection in micro-droplets. Chem commun. 48, 6490-6492 (2012).

27. Rengaraj, A. et al. Electrodeposition of flower-like nickel oxide on CVD-grown graphene to develop an electrochemical nonenzymatic biosensor. J Mater Chem B. 3, 6301-6309 (2015).

28. Mai, Y., Tu, J., Gu, C. \& Wang, X. Graphene anchored with nickel nanoparticles as a high-performance anode material for lithium ion batteries. J Power Sources. 209, 1-6 (2012).

29. Li, Q. et al. Highly efficient visible-light-driven photocatalytic hydrogen production of CdS-cluster-decorated graphene nanosheets. J Am Chem Soc. 133, 10878-10884 (2011).

30. Mann, M. A., Helfrick, J. C. Jr. \& Bottomley, L. A. Diagnostic Criteria for the Characterization of Quasireversible Electron Transfer Reactions by Cyclic Square Wave Voltammetry. Anal chem. 86, 8183-8191 (2014).

31. Mu, Y., Jia, D., He, Y., Miao, Y. \& Wu, H. L. Nano nickel oxide modified non-enzymatic glucose sensors with enhanced sensitivity through an electrochemical process strategy at high potential. Biosens Bioelectron. 26, 2948-2952 (2011).

32. Zhang, Y., Wang, Y., Jia, J. \& Wang, J. Nonenzymatic glucose sensor based on graphene oxide and electrospun NiO nanofibers. Sensor Actuat B-Chem. 171, 580-587 (2012).

33. Zhang, W. D., Chen, J., Jiang, L. C., Yu, Y. X. \& Zhang, J. Q. A highly sensitive nonenzymatic glucose sensor based on NiO-modified multi-walled carbon nanotubes. Microchim acta. 168, 259-265 (2010).

34. Lv, W., Jin, F. M., Guo, Q., Yang, Q. H. \& Kang, F. DNA-dispersed graphene/NiO hybrid materials for highly sensitive non-enzymatic glucose sensor. Electrochim Acta. 73, 129-135 (2012).

35. Sun, A., Zheng, J. \& Sheng, Q. A highly sensitive non-enzymatic glucose sensor based on nickel and multi-walled carbon nanotubes nanohybrid films fabricated by one-step co-electrodeposition in ionic liquids. Electrochim Acta. 65, 64-69 (2012).

36. Wang, J., Thomas, D. F. \& Chen, A. Nonenzymatic electrochemical glucose sensor based on nanoporous PtPb networks. Anal Chem. 80, 997-1004 (2008).

37. Niu, X., Lan, M., Zhao, H. \& Chen, C. Highly sensitive and selective nonenzymatic detection of glucose using three-dimensional porous nickel nanostructures. Anal Chem. 85, 3561-3569 (2013).

38. An, L., Zhao, T., Shen, S. Y., Wu, Q. X. \& Chen, R. Alkaline direct oxidation fuel cell with non-platinum catalysts capable of converting glucose to electricity at high power output. J power sources. 196, 186-190 (2011).

\section{Acknowledgements}

This work was financially supported by the Natural Science Foundation of Jiangxi Province (20152ACB21019), the National Natural Science Foundation of China (2156060113, 51238002 and 21566025).

\section{Author Contributions}

Z.W. and G.Z. conceived the idea. W.L. performed the material fabrication experiments. W.L. and S.C. conducted the electrochemical tests. J.J. performed SEM and TEM characterizations. Z.W., G.Z. and W.L. co-wrote the paper. All authors discussed the results and commented on the manuscript.

\section{Additional Information}

Supplementary information accompanies this paper at http://www.nature.com/srep

Competing financial interests: The authors declare no competing financial interests.

How to cite this article: Zeng, G. et al. Highly Dispersed NiO Nanoparticles Decorating graphene Nanosheets for Non-enzymatic Glucose Sensor and Biofuel Cell. Sci. Rep. 6, 36454; doi: 10.1038/srep36454 (2016).

Publisher's note: Springer Nature remains neutral with regard to jurisdictional claims in published maps and institutional affiliations.

(c) (i) This work is licensed under a Creative Commons Attribution 4.0 International License. The images or other third party material in this article are included in the article's Creative Commons license, unless indicated otherwise in the credit line; if the material is not included under the Creative Commons license, users will need to obtain permission from the license holder to reproduce the material. To view a copy of this license, visit http://creativecommons.org/licenses/by/4.0/

(C) The Author(s) 2016 